\title{
Studying and Analyzing the Evaluation Dimensions of E-learning Platforms Relying on a Software Engineering Approach
}

\author{
http://dx.doi.org/10.3991/ijet.v11i01.4924 \\ Mohammed Ouadoud $^{1}$, Mohamed Yassin Chkouri ${ }^{2}$, Amel Nejjari ${ }^{2}$, Kamal Eddine El Kadiri ${ }^{1}$ \\ ${ }^{1}$ LIROSA Lab, UAE, Faculty of Sciences, Tetouan, Morocco \\ 2 SIGL Lab, UAE, National School of Applied Sciences, Tetouan, Morocco
}

\begin{abstract}
We are currently witnessing the launch and development of a large number of distance training devices in Moroccan universities, whose main objective is to meet society's requirements and the knowledge economy, which is fully emerging. All of the devices are based on the use of elearning platforms, which can be problematic for designers for different reasons (costs, utility, usability, etc.). Being conscious of the impact of these technological tools on learning, we propose a methodical approach that identifies the essential criteria for evaluation of e-learning platforms to fit the needs of teachers and learners from analysis of the evaluation dimensions in multimedia documents, particularly through the dimensions of utility and usability.
\end{abstract}

Index Terms-e-learning platforms evaluation, evaluation approach, evaluation process, e-learning platform, software engineering, software engineering approach.

\section{INTRODUCTION}

One of the essential features of knowledge economy is the acceleration of interactive software life cycles, which are part of e-learning platforms. The choice of these platforms, which constitute the cornerstone of initial and continuing training systems, is not obvious to most users. But why is this so difficult?

As part of our study, we will show that choosing between the various tools available on the market forced us to identify the challenges and the specific needs. It was crucial to ensure these tools would provide rich services motivated by the online sharing of structured information and interactivity among different users. To this, we added the tracking services of the learning paths of different users, notably learners.

It was obvious that the use of any tool in the field of education and training had to be justified according to its pedagogical interest and its response to the needs of the learners, but if the platform is supposed to address the spatial and temporal constraints between tutors and learners, it must not hinder the learning process.

Consequently, any random choice that entails a loss of money, effort and time challenges us and invites us to ask the following questioning:

On the one hand, how can we choose an e-learning platform that meets the norms and standards as they are acknowledged in distance education devices?

On the other hand, e-learning platforms are objects of evaluation, so to what degree of training specificity can they respond? What are the choices in terms of multimedia engineering on which we must analyze these platforms? What norms and standards do the requirements meet in evaluation of these platforms?

These issues and others are the subject of the investigations as part of our approach to judge its intake for experimentation purposes.

For our study, reading of the specialized literature in the e-learning platforms analysis shows two orientations. The first is dedicated to the technical analysis (computer language, script, metadata), and the second covers the pedagogical extent of these platforms and the development of the learners' skills.

Our approach is oriented toward a reconciliation of these two orientations. The technological and pedagogical are not mutually exclusive; however, crossing their elements in a goal or technology is at the pedagogical center.

To concretize our approach, in the "theoretical frame" section, we initially took the evaluation dimensions of interactive systems conducted by Senach [3], Tricot [4] and ISO 25010 [18]. Then we categorized these works and the various discussions $[1,2]$. After analysis, we retained the dimensions of utility and usability.

Then, in the "analysis of assessment dimensions" section, we followed a specific methodology for analyzing the evaluation dimensions obtained according to the three steps indicated:

- Comparison of studied outcomes,

- Personal position relative to the outcomes,

- Analysis and results (choose criteria and tools suitable for evaluation of the platforms).

This section mainly consists of three sub-sections:

1. Utility analysis: In this sub-section, we will categorize the utility characteristics discussed, according to various studies $[3,4,18,20]$. After the analysis, we retained six utility characteristics. Thereafter, we attempted to subject the tools of currently recognized e-learning platforms to filter the criteria that met the pedagogical principles of training, based on various studies $[6,7]$, to check the quality and the presence of the tools available to the various players in distance training. Then we checked their utility and their operability through interactive technologies that met the retained characteristics [18]. 
2. Usability analysis: In this sub-section, we categorize the most important usability criteria, according to various studies $[11,9,17,22,5,20$, $16,4,21,8,12,13,24,23,18,10]$. After the analysis, we selected eight usability criteria to be part of our evaluation gait.

3. Evaluation approach of platforms: In this subsection we present the measures and criteria adapted for the evaluation of e-learning platforms according to a scalable approach and synthesis of the two analyzed dimensions.

\section{E-LEARNING PLATFORM}

\section{A. Definition}

As we defined OVAREP [6], the e-learning platform is a computing device that groups several tools and ensures the educational conduits. Across dedicated platforms to the $\mathrm{ODL}^{3}$, all conduits are preserved and expanded for the learner, tutor, administrator, etc. within the e-learning platform.

Thereby, the tools offered by these platforms enable tutors and learners to communicate individually or collectively and discuss themes and shared documents.

The learner is invited to consult on the course, to realize the homework, to follow its development, and to receive self-generated feedback or feedback given by the tutor. In this environment, the learner exchanges his knowledge, his remarks and contributions (production or document) with other learners to self-evaluate and transmit his work to a teacher, whether it is individually or collectively.

A training coordinator is responsible for the learners' inscription management, of the time, and of the rhythms of the formation and activity of the teaching team.

The teacher (course designer) is responsible for the preparation of courses and tutors. The tutor is supposed to bring the necessary support to the learners at both cognitive and methodological levels. The tutor's role differs according to the pedagogical presuppositions inherent to the e-learning platforms.

He can be an animator in a collaborative educational device, facilitator in a constructivist educational device, organizer of learning situations conducive to dialogue with a view to cause and resolve conflicts in a socialconstructionist educational device; presenter of information via a structured, hierarchical, and deductive in a cognitivist educational device; or an expert on a transmissive educational device.

The administrator plays a technical role and cannot be confused with the role of the coordinator who has as a function in the following tasks:

- Installs and maintains the system,

- Manages access and rights,

- Creates links with external information systems (school, catalog, teaching resources, etc.).

\section{B. Platform features}

An e-learning platform exists to bring answers to the following problems:

\footnotetext{
${ }^{3}$ ODL: Open and distance learning.
}

- Expand the training offered through the ODL and allow those who find training constraints to have opportunities to overcome them,

- Access to the best management of time jobs by reducing the supply in presential training,

- Develop exchange, inter-actors of training,

- Innovate the teaching practices by using new technologies for communication and training,

- Introduce other modalities of training such as management of collaborative projects,

- Foster the role of tutoring that allows reducing the sensation of isolation, often the cause of stalling and abandonment.

An e-learning platform fits well in several pedagogical models. We defined our expectations in matters of content and teaching modalities for all the actors: learners, integrators, tutors, coordinators and administrators.

Learners are invited to

- Attend pedagogical activities that take various forms, both specific and general (problems, simulations, QCM, tests self-correcting),

- Include interactive teaching resources in various formats (text, image, audio, video, PDF, Flash),

- Realize situations for assessments,

- Access collaborative working from shared documents.

The learning path is divided into two entities:

- Entity 1 consists of creating modules that are broken into several units that contain various resources (documents, activities, quiz) and learning pathoriented supports (individual or a group),

- Entity 2 consists of achieving a set of activities (in relation to the objective of the module) as part of project-based teaching, courses oriented activities.

Teachers (course designers) are responsible for the preparation of training courses with regard to

- Creation of the teaching resources interface with the training management systems (AICC, SCORM, etc.),

- Sharing educational resources (course modules, evaluations, etc.),

- Planning of pedagogical resources.

Tutors are responsible for

- Taking charge of learners by an individual tracking system, animation and / or moderation of forums,

- Initializing the conversation within the chat, which is responsible,

- Follow-up the learners in videoconference,

- Monitoring activities and proposed projects,

- Planning the interventions,

- Monitoring the groups' management.

Administrators and coordinators are responsible for customizing the platform with regard to

- Establishing the groups,

- Monitoring the activities of teachers,

- Managing the courses,

- Customizing the platform,

- Managing the roles. 




Figure 1. Dimensions of evaluation, adapted by Senach [3]

\section{THEORETICAL FRAME}

E-learning platforms, like any software, must be subjected to a set of criteria that make the process of evaluation possible. These criteria are order, pedagogical, technical and ergonomic functions, etc. As part of this section, we will introduce and synthesize our theoretical foundation, taking into account the approaches of Senach [3] and Tricot [4] as well as the ISO 25010 standard [18] and the various discussions they confront $[1,2]$.

\section{A. Approach of Senach}

In light of Senach's work, including 'L'évaluation Ergonomique des Interfaces Homme-Machine: Une Revue de la Littérature" [3], we distinguished three main evaluation dimensions of interactive systems: utility, usability and aesthetics.

In a similar fashion, Figure 1 presents evaluation criteria of the three main evaluation dimensions adapted by Senach.

Regarding these three dimensions, other researchers, such as Bastien and Scapin, found that the aesthetic dimension is sometimes regarded as a component of satisfaction on the part of the user, as are the preferences of the user [1]. In addition, the aesthetic dimension is suspicious of great subjectivity and is likely to be abandoned.

\section{B. Approach of Tricot}

Tricot added the dimension of acceptability to these three dimensions (utility, usability and aesthetics) [3]: in other words, feeling positive or negative with regard to the product, "intention" of use depending on many parameters: motivation, affects, culture, values [4]. Figure 2 presents criteria that are possible for evaluation of utility, usability and acceptability [4].

In its three dimensions, Huart found that the notions of utility and usability are often discussed in the literature [2].

In what follows, the ISO 25010 standard completes what has been developed by different studies and presents a model of the quality of interactive systems of the eight characteristics.

\section{Approach of ISO 25010 standard}

In the quality model of interactive systems, the most famous characteristics are those of the ISO / IEC 9126-1:

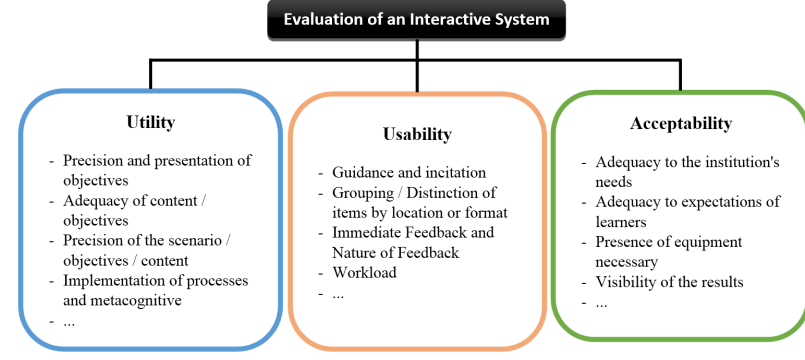

Figure 2. Presentation of measures and criteria for evaluation by inspection of a $\mathrm{HSI}^{4}$ [4]

TABLE I.

QUALITY MODEL INTERACTIVE SYSTEMS OF ISO 25010 [18]

\begin{tabular}{|c|c|}
\hline Characteristic & Sub Characteristic \\
\hline \multirow{3}{*}{ Functional suitability } & Functional completeness \\
\hline & Functional correctness \\
\hline & Functional appropriateness \\
\hline \multirow{3}{*}{ Performance efficiency } & Time behavior \\
\hline & Resource utilization \\
\hline & Capacity \\
\hline \multirow{2}{*}{ Compatibility } & Co-existence \\
\hline & Interoperability \\
\hline \multirow{6}{*}{ Usability } & Appropriateness recognizability \\
\hline & Learnability \\
\hline & Operability \\
\hline & User error protection \\
\hline & User interface aesthetics \\
\hline & Accessibility \\
\hline \multirow{4}{*}{ Reliability } & Maturity \\
\hline & Availability \\
\hline & Fault tolerance \\
\hline & Recoverability \\
\hline \multirow{5}{*}{ Security } & Confidentiality \\
\hline & Integrity \\
\hline & Non-repudiation \\
\hline & Accountability \\
\hline & Authenticity \\
\hline \multirow{5}{*}{ Maintainability } & Modularity \\
\hline & Reusability \\
\hline & Analysability \\
\hline & Modifiability \\
\hline & Testability \\
\hline \multirow{3}{*}{ Portability } & Adaptability \\
\hline & Installability \\
\hline & Replaceability \\
\hline
\end{tabular}

2001 [20]. These characteristics, were originally developed in 2001 and revised in 2011 by the ISO / IEC 25010: 2011 [18], which incorporates the same software quality characteristics with some modifications.

The quality model of interactive systems of ISO 25010 standard consists of eight characteristics: functional suitability, performance efficiency, compatibility, usability, reliability, security, maintainability, and portability. Each characteristic is composed of a set of related sub-characteristics.

Table I presents a quality model interactive system of the eight main evaluation characteristics of the ISO 25010 standard.

\footnotetext{
${ }^{4}$ HSI: Human-computer Interaction
} 


\section{SPECIFICITIES ANALYSIS OF PLATFORMS}

In the project, we followed a detailed evaluation strategy of the platform's evaluation criteria while referring to two retained evaluation dimensions.

\section{A. Utility analysis}

In the development of interactive software, the most popular utility criteria were presented in the "theoretical frame" section. Thus, in Table II, we selected the basic criteria that constituted the cornerstone of the utility dimension, and we have them placed in comparison to users' characteristics established by different studies, depending on the possible declensions of the cited criteria.

We distinguished (see Table II) that the functional ability is often recommended in most studies. For this, we retained this characteristic because it is often the subject of interactive systems evaluation.

In 1990, Senach treated the functional capacity. Then, in 2001, ISO 9126-1 standard completed what Senach started and nicknamed this characteristic "functionality," which consists of sub-related characteristics in particular: compatibility/interoperability and security.

In addition, in 2011, the ISO 25010 standard reviewed what had been originally developed by ISO 9126-1 and incorporated the same software quality characteristics with some changes. Among these changes, we found that this standard gave more importance to compatibility and security, which originally were the sub-characteristics of the functionality characteristic of ISO 9126-1 standard, nicknamed "functional suitability."

Thereby, we also retained compatibility and security.

Moreover, we added the characteristic of portability because it is practically discussed (see Table II), and it gives more importance to the adaptability of the platforms for mobile devices because it facilitates distance learning.

We, therefore, selected four criteria of utility, namely:

- Functional suitability,

- Compatibility,

- Security,

- Portability.

Subsequently, we used these retained criteria, in comparison to users' characteristics established by different studies, based on Table III. After analysis, we found that the four criteria of usefulness address the characteristics of ISO 25010 because they are often recommended in most studies.

Usually, the ISO 25010 consists of eight related characteristics; however, in this dimension, we treated just six characteristics of this standard: functional suitability, performance efficiency, compatibility, security, maintainability and portability. These characteristics, in our view, are best suited to assessing the usefulness of the e-learning platforms.

Thus, the two other characteristics of ISO 25010: usability and reliability will be treated in the usability dimension.

In what follows, we used the currently recognized functionality tools of e-learning platforms to filter the criteria that meet the six characteristics of utility.
TABLE II.

COMPARISON OF CHARACTERISTICS USERS IN THE DESIGN INTERFACE OF UTILITY

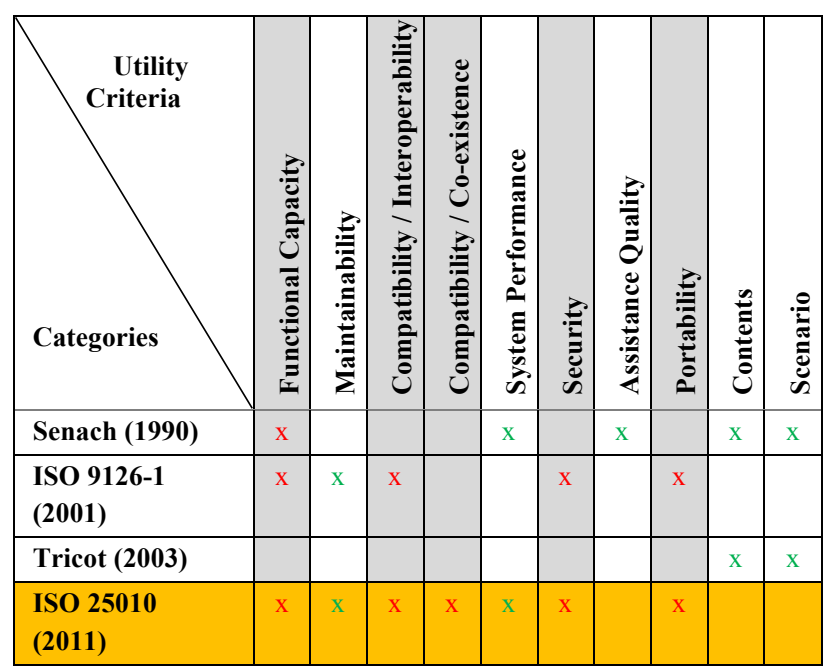

1) Analysis of functionality tools

Based on Ahmed Lablidi's Table and OVAREP's study [6] as well as Aska's Table and Anne Bouthry's study [7], after analysis, we tried to adapt these criteria to the specific needs of our approach. Thus, a set of functionalities were identified for each actor of the platform to perform his task. Among these IT functionalities, we are providing actors tools of communication, monitoring, sharing, security, interoperability and organization, etc. Table III associates the criteria to the given tools at disposition for each actor.

Five actors were distinguished:

- Learners,

- Teachers (course creators), responsible for the preparation of tutors and training courses,

- Tutor, responsible for monitoring learners,

- Coordinator, responsible for the platform integration into the overall operations of the tutors establishment,

- And administrator, responsible for customizing the platform.

For each actor, we analyzed the breadth of functionalities to which he has access, integration of these functionalities, ease of use, and requirements with regard to competence.

Conscious that platforms are not generic to evaluate adequacy between technological tools and pedagogical intakes for the different actors, we evaluated the ease of editing courses, the process of monitoring and coaching, and the interactive aspects among users of the platform.

We know that the mission of a platform is made available to users through the pedagogical activities. Thus, the functionalities offered would first help the different actors fulfill their respective tasks and enable cooperation and communication among the users.

Our analytical work advocated determining the functionalities by using a checklist (see Table III) and then checking their utilities and categorical location, according to a method of analysis by characteristic. 
TABLE III.

SELECTED CRITERIA AND TOOLS FOR CHOOSING AN E-LEARNING PLATFORM

\begin{tabular}{|c|c|c|}
\hline Actors & Criteria & Tools \\
\hline \multirow[t]{9}{*}{ Learner } & Synchronous communication & Chat, virtual classroom (videoconferencing / webinar) \\
\hline & Asynchronous communication & Forum, messaging, mailing \\
\hline & Document Sharing & $\begin{array}{l}\text { Deposit space of document, virtual library, database, forum, Wiki, Dropbox, } \\
\text { Shared folders }\end{array}$ \\
\hline & Historical of documents & Social networks, forum \\
\hline & Organization & Calendar, Post-it, dashboard \\
\hline & Evaluation & Tests, dashboard, portfolio, quiz \\
\hline & Collaboration & Wiki, dlassroom (videoconferencing / webinar), portfolio, forum \\
\hline & Plagiarism Detection & Plagiarism detection tools \\
\hline & Certification & Followed certificate of training \\
\hline \multirow[t]{4}{*}{ Teacher, tutor } & Registration of learners & Calendar, dashboard \\
\hline & Groups management & Registration to one or more groups, calendar, dashboard \\
\hline & Tracking of learners & $\begin{array}{l}\text { Tracking, number of times that the learner has logged in, the connections } \\
\text { dates, executed activities (courses, discussions, forums, tests, etc.), \% } \\
\text { success, progress monitoring }\end{array}$ \\
\hline & Management of tests & $\begin{array}{l}\text { Generator of QUIZ and test, self-evaluation tests, managing notes: average } \\
\text { calculation, displaying notes, report on the test results }\end{array}$ \\
\hline \multirow{5}{*}{$\begin{array}{l}\text { Administrator, } \\
\text { coordinators }\end{array}$} & Assignment of courses to learners and tutors & Data processing by group and tutors \\
\hline & Dissemination of results & Import and export formats supported by different file types \\
\hline & Management of user roles & Multi-profile management (learners, teacher, tutor, integrator / author) \\
\hline & Course transfer from one platform to another & Example: transfer of a course on Moodle platform to Claroline platform \\
\hline & Customizing the platform & Managing roles, groups, modules, access rights, etc. \\
\hline \multirow{5}{*}{$\begin{array}{l}\text { Teacher, } \\
\text { course } \\
\text { designer }\end{array}$} & Multimedia content & Audio, video, flash, etc. \\
\hline & Resource Management & Filing space of documents \\
\hline & IMS interoperability standards & SCORM, IMS QTI, AICC, IMS XML \\
\hline & Support of multiple authors & $\begin{array}{l}\text { The right to create, manage its own course, and give the right of access to } \\
\text { another teacher }\end{array}$ \\
\hline & Import and export & Import and export of the tests \\
\hline \multirow[t]{12}{*}{ All actors } & Presence of other actors & Awareness \\
\hline & Identification & Visit card, profile, badge and dashboard. \\
\hline & Security & $\begin{array}{l}\text { Possibility to use SSL, security by login / password, Assigning username and } \\
\text { password, security barrier, backup system. }\end{array}$ \\
\hline & Compatibility with common browsers & Compatibility with common browsers such as: Firefox, Chrome, Opera, etc. \\
\hline & File diffusion means & RSS \\
\hline & Used technology & PHP, JAVA, ASP, PITON, etc. \\
\hline & Used Database & SQL, NoSQL \\
\hline & Interaction with other operating systems & Unix, Linux, Mac OS X, Microsoft Windows, FreeBSD, etc. \\
\hline & Interaction with other databases & PostgreSQL, SQLite, MS SQL, MySQL, Oracle DB, MariaDB, Percona, etc. \\
\hline & Possibility of using plugins & Such as PDF, Excel, PowerPoint, Word, etc. \\
\hline & Portability & Adaptation to mobile terminals \\
\hline & Adapting to different training devices & Creating MOOC or SPOC \\
\hline
\end{tabular}

We usually distinguished six characteristics previously retained:

- Functional suitability,

- Performance efficiency,

- Compatibility,

- Security,

- Maintainability,

- Portability.

For each of the characteristics and its subcharacteristics, we analyzed the functionality with which it has access and the integration of these characteristics to available tools for each characteristic based on the criteria and selected tools in Table III.
In the following, the six essential characteristics were retained to conduct distance training with functionality tools to meet the previously outlined criteria (see Table III).

\section{2) Functional suitability}

Functional suitability means "the degree to which a product or system provides functions that meet stated and implied needs when used under specified conditions" [18].

Table IV projects the essential functionalities for functional suitability and the sub-characteristics meeting the previously outlined criteria. Three sub-characteristics related to functional suitability were distinguished and defined in accordance with ISO 25010: 
- Functional completeness: "the degree to which the set of functions covers all the specified tasks and user objectives"

- Functional correctness: "the degree to which a product or system provides the correct results with the needed degree of precision"

- Functional appropriateness: "the degree to which the functions facilitate the accomplishment of specified tasks and objectives"

TABLE IV.

FUNCTIONAL SUITABILITY TOOLS ADAPTED FOR CHOOSING AN ELEARNING PLATFORM

\begin{tabular}{|c|c|c|}
\hline Functional suitability & YES & NO \\
\hline \multicolumn{3}{|l|}{ Functional completeness } \\
\hline \multicolumn{3}{|l|}{ Forum } \\
\hline \multicolumn{3}{|l|}{ Synchronous causerie (cat / chat) } \\
\hline \multicolumn{3}{|l|}{$\begin{array}{l}\text { Virtual Classroom (videoconferencing / } \\
\text { webinar) }\end{array}$} \\
\hline \multicolumn{3}{|l|}{ Sharing documents } \\
\hline \multicolumn{3}{|l|}{ Calendar } \\
\hline \multicolumn{3}{|l|}{ Awareness (list of connected people) } \\
\hline \multicolumn{3}{|l|}{ Tests management } \\
\hline \multicolumn{3}{|l|}{ Collaboration (Wiki) } \\
\hline \multicolumn{3}{|l|}{$\begin{array}{ccc}\begin{array}{c}\text { Learners' } \\
\text { schedule...) }\end{array} & \text { management } \quad \text { (registration, } \\
\end{array}$} \\
\hline \multicolumn{3}{|l|}{ Learners management in working groups } \\
\hline \multicolumn{3}{|l|}{ Users roles management } \\
\hline \multicolumn{3}{|l|}{ Customizable platform } \\
\hline \multicolumn{3}{|l|}{$\begin{array}{l}\text { Advancement Scale or progression percentage } \\
\text { in the course }\end{array}$} \\
\hline \multicolumn{3}{|l|}{ Resource Management (course) } \\
\hline \multicolumn{3}{|l|}{ Support of multiple authors } \\
\hline \multicolumn{3}{|l|}{ Functional correctness } \\
\hline \multicolumn{3}{|l|}{$\begin{array}{l}\text { Management of working time of learners and } \\
\text { Teachers }\end{array}$} \\
\hline \multicolumn{3}{|l|}{ Results and notes } \\
\hline \multicolumn{3}{|l|}{ Notes display } \\
\hline \multicolumn{3}{|l|}{ Tracking statistics of course } \\
\hline \multicolumn{3}{|l|}{ Control Connections (tracking of learners) } \\
\hline \multicolumn{3}{|l|}{ Report on the test results } \\
\hline \multicolumn{3}{|l|}{ Glossary } \\
\hline \multicolumn{3}{|l|}{ Report on the frequency or the use of a course } \\
\hline \multicolumn{3}{|l|}{ Functional appropriateness } \\
\hline \multicolumn{3}{|l|}{ Certification (certificate of training follow-up) } \\
\hline \multicolumn{3}{|l|}{ Foyer (family group) } \\
\hline \multicolumn{3}{|l|}{ Registration chat } \\
\hline \multicolumn{3}{|l|}{ Messaging } \\
\hline \multicolumn{3}{|l|}{ Plagiarism detection tools } \\
\hline $\begin{array}{l}\text { RSS / podcast : means of distributing files } \\
\text { (audio, video or other) }\end{array}$ & & \\
\hline
\end{tabular}

TABLE V.

PERFORMANCE EFFICIENCY TOOLS ADAPTED FOR CHOOSING AN ELEARNING PLATFORM

\begin{tabular}{|l|l|l|}
\hline \multicolumn{1}{|c|}{ Performance efficiency } & YES & NO \\
\hline \multicolumn{2}{|l|}{ Resource utilization } & \\
\hline $\begin{array}{l}\text { Is that platform functionalities tools meet the } \\
\text { distance requirements Learning }\end{array}$ & \\
\hline Capacity & & \\
\hline $\begin{array}{l}\text { Is that the platform meets all the distance } \\
\text { requirements learning }\end{array}$ & & \\
\hline Assistance quality & & \\
\hline
\end{tabular}

3) Performance efficiency

Performance efficiency means "the performance relative to the amount of resources used under stated conditions" [18].

In Table $\mathrm{V}$, we project the essential functionalities for performance efficiency and the sub-characteristics meeting previously outlined criteria. Two subcharacteristics related to performance efficiency were distinguished and defined in accordance with ISO 25010:

- Resource utilization: "degree to which the amounts and types of resources used by a product or system, when performing its functions, meet requirements"

- Capacity: "degree to which the maximum limits of a product or system parameter meet requirements"

\section{4) Compatibility}

Compatibility signifies "the degree to which a product, system or component can exchange information with other products, systems or components, and/or perform its required functions, while sharing the same hardware or software environment" [18].

Table VI presents the essential functionalities for compatibility and the sub-characteristics meeting the previously outlined criteria. Two sub-characteristics related to compatibility were distinguished and defined:

- Co-existence: "degree to which a product can perform its required functions efficiently while sharing a common environment and resources with other products, without detrimental impact on any other product"

- Interoperability: "degree to which two or more systems, products or components can exchange information and use the information that has been exchanged"

\section{5) Security}

Security means "the degree to which a product or system protects information and data so persons or other products or systems have the degree of data access appropriate to their types and levels of authorization" [18].

TABLE VI.

COMPATIBILITY TOOLS ADAPTED FOR CHOOSING AN E-LEARNING PLATFORM

\begin{tabular}{|c|c|c|}
\hline Compatibility & YES & NO \\
\hline \multicolumn{3}{|l|}{ Co-existence } \\
\hline \multicolumn{3}{|l|}{$\begin{array}{l}\text { Course transfer from one platform to another } \\
\text { of the same type }\end{array}$} \\
\hline \multicolumn{3}{|l|}{$\begin{array}{l}\text { SCORM (allows creating grains of course, } \\
\text { reusable and interoperable). }\end{array}$} \\
\hline \multicolumn{3}{|l|}{$\begin{array}{l}\text { IMS QTI (set of specifications allowing } \\
\text { interoperability to test systems) }\end{array}$} \\
\hline \multicolumn{3}{|l|}{$\begin{array}{l}\text { AICC (sets the interoperability between the } \\
\text { platform and content) }\end{array}$} \\
\hline \multicolumn{3}{|l|}{ IMS XML } \\
\hline \multicolumn{3}{|l|}{ Interoperability } \\
\hline \multicolumn{3}{|l|}{ Information and application sharing } \\
\hline \multicolumn{3}{|l|}{ Import and export of resources } \\
\hline \multicolumn{3}{|l|}{ Possibility of using plugins (Word, Excel, etc.) } \\
\hline Technology used (PHP, J2EE, ASP...) & & \\
\hline
\end{tabular}


Table VII shows the essential functionalities for security and their sub-characteristics meeting the previously outlined criteria. Five sub-characteristics related to security were distinguished and defined in accordance with ISO 25010:

- Confidentiality: "degree to which a product or system ensures that data are accessible only to those authorized to have access"

- Integrity: "degree to which a system, product or component prevents unauthorized access to, or modification of, computer programs or data"

- Non-repudiation: "degree to which actions or events can be proven to have taken place, so that the events or actions cannot be repudiated later"

- Accountability: "degree to which the actions of an entity can be traced uniquely to the entity"

- Authenticity: "degree to which the identity of a subject or resource can be proved to be the one claimed."

\section{6) Maintainability}

Maintainability means "the degree of effectiveness and efficiency with which a product or system can be modified by the intended maintainers" [18].

In Table VIII, the essential functionalities for maintainability and for their sub-characteristics meeting the previously outlined criteria. Five sub-characteristics related to maintainability were distinguished and defined in accordance with ISO 25010 :

- Modularity: "the degree to which a system or computer program is composed of discrete components such that a change to one component has minimal impact on other components"

- Reusability: "the degree to which an asset can be used in more than one system, or in building other assets"

- Modifiability: "the degree to which a product or system can be effectively and efficiently modified without introducing defects or degrading existing product quality"

- Testability: "the degree of effectiveness and efficiency with which test criteria can be established for a system, product or component and tests can be performed to determine whether those criteria have been met"

\section{7) Portability}

Portability signifies "the degree of effectiveness and efficiency with which a system, product or component can be transferred from one hardware, software or other operational or usage environment to another" [18].

Table IX shows the essential functionalities for portability and for their sub-characteristics meeting the previously outlined criteria. Three sub-characteristics related to portability were distinguished and defined in accordance with ISO 25010:

- Adaptability: “degree to which a product or system can effectively and efficiently be adapted for different or evolving hardware, software or other operational or usage environments"
TABLE VII.

SECURITY TOOLS ADAPTED FOR CHOOSING AN E-LEARNING PLATFORM

\begin{tabular}{|l|l|l|}
\hline \multicolumn{1}{|c|}{ Security } & YES & NO \\
\hline Confidentiality & & \\
\hline Secured by login / password & & \\
\hline Assigning access rights & & \\
\hline Integrity & & \\
\hline Ability to use SSL & & \\
\hline Non-repudiation & & \\
\hline Tracking system & & \\
\hline Backup system & & \\
\hline Accountability & & \\
\hline Barrier of security & & \\
\hline Authenticity & & \\
\hline Assigning username and password & & \\
\hline Identity card (visit card / profile) &
\end{tabular}

TABLE VIII.

MAINTAINABILITY TOOLS ADAPTED FOR CHOOSING AN E-LEARNING PLATFORM

\begin{tabular}{|l|l|l|}
\hline \multicolumn{1}{|c|}{ Maintainability } & YES & NO \\
\hline Modularity & & \\
\hline $\begin{array}{l}\text { Is that the platform contains of discrete plugins } \\
\text { Reusability }\end{array}$ & & \\
\hline $\begin{array}{l}\text { Interaction with other operating systems } \\
\text { (multi-operating systems option) }\end{array}$ & & \\
\hline $\begin{array}{l}\text { Interaction with other databases (multi- } \\
\text { database option) }\end{array}$ & & \\
\hline Modifiability & & \\
\hline Modifiability of the system without errors & & \\
\hline Testability & \\
\hline Maintenance and updating & \\
\hline
\end{tabular}

TABLE IX

PORTABILITY TOOLS ADAPTED FOR CHOOSING AN E-LEARNING PLATFORM

\begin{tabular}{|l|l|l|}
\hline \multicolumn{1}{|c|}{ Portability } & YES & NO \\
\hline Adaptability & & \\
\hline Adaptation to mobiles terminals & & \\
\hline Compatibility with common browsers & & \\
\hline $\begin{array}{l}\text { Adapting to different training devices } \\
\text { (creating MOOC or SPOC) }\end{array}$ & \\
\hline Installability & & \\
\hline Instability of without errors platform & \\
\hline Replaceability & & \\
\hline Replaceability with the new platform version & & \\
\hline
\end{tabular}

- Installability: "degree of effectiveness and efficiency with which a product or system can be successfully installed and/or uninstalled in a specified environment"

- Replaceability: "degree to which a product can replace another specified software product for the same purpose in the same environment."

\section{B. Usability analysis}

In software development and interface design, the bestknown usability criteria are ones by Nielsen [9]. The "Nielsen ten usability criteria" were originally developed in 1990 and revised in 1994 after a factor analysis of 249 usability problems. Nielsen's ten principles are composed of a general list and offer broad categories. 
TABLE X.

COMPARISON OF CHARACTERISTICS USERS IN THE DESIGN INTERFACE OF USABILITY

\begin{tabular}{|c|c|c|c|c|c|c|c|c|c|c|c|c|c|c|c|c|c|c|c|c|c|c|}
\hline Usability Criteria & 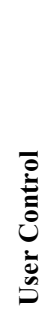 &  &  & 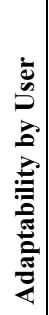 & 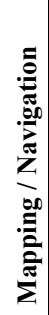 & 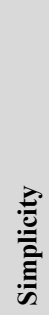 &  & 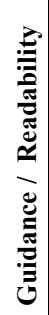 & 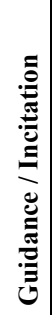 & 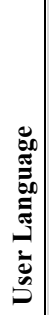 &  &  & 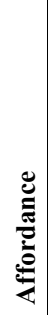 & 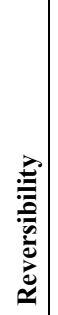 & 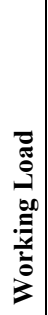 & 党 & 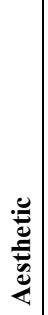 & 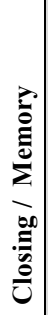 & 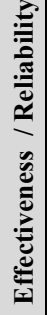 & 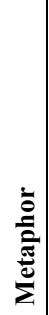 & 㟒 & : \\
\hline Norman (1988) & & $\mathrm{x}$ & $\mathrm{x}$ & & $\mathrm{x}$ & $\mathrm{x}$ & $\mathrm{x}$ & & & & $\mathrm{x}$ & & & $\mathrm{x}$ & & & & $\mathrm{x}$ & & & & \\
\hline Nielson (1995) & $\mathrm{x}$ & $\mathrm{x}$ & $\mathrm{x}$ & & & & $\mathrm{x}$ & & & $\mathrm{x}$ & $\mathrm{x}$ & $\mathrm{x}$ & & $\mathrm{x}$ & & & $\mathrm{x}$ & $\mathrm{x}$ & & $\mathrm{x}$ & & \\
\hline Gerhardt-Powals (1996) & & $\mathrm{x}$ & & & & & & $\mathrm{x}$ & & & $\mathrm{x}$ & $\mathrm{x}$ & & & $\mathrm{x}$ & & & & $\mathrm{x}$ & & & \\
\hline ISO 9241-11 (1998) & & & & & & & & & & & & $\mathrm{x}$ & & & & & & & $\mathrm{x}$ & & & $\mathrm{x}$ \\
\hline Bastien et Scapin (2001) & $\mathrm{x}$ & & $\mathrm{x}$ & $\mathrm{x}$ & $\mathrm{x}$ & & $\mathrm{x}$ & $\mathrm{x}$ & $\mathrm{x}$ & & $\mathrm{x}$ & $\mathrm{x}$ & $\mathrm{x}$ & & $\mathrm{x}$ & & & & & $\mathrm{x}$ & & \\
\hline ISO 9126-1 (2001) & & $\mathrm{x}$ & & $\mathrm{x}$ & & $\mathrm{x}$ & & & & & & & & & & & & & $\mathrm{x}$ & & $\mathrm{x}$ & \\
\hline Baker et al. (2002) & $\mathrm{x}$ & $\mathrm{x}$ & $\mathrm{x}$ & & & $\mathrm{x}$ & $\mathrm{x}$ & $\mathrm{x}$ & & & & & & & & & & & & & & \\
\hline Tognazzini (2003) & & $\mathrm{x}$ & $\mathrm{x}$ & & $\mathrm{x}$ & $\mathrm{x}$ & & $\mathrm{x}$ & & & $\mathrm{x}$ & $\mathrm{x}$ & & & & $\mathrm{x}$ & & & & $\mathrm{x}$ & & \\
\hline Tricot et Al. (2003) & $\mathrm{x}$ & & $\mathrm{x}$ & $\mathrm{x}$ & $\mathrm{x}$ & & $\mathrm{x}$ & & $\mathrm{x}$ & & $\mathrm{x}$ & $\mathrm{x}$ & $\mathrm{x}$ & & $\mathrm{x}$ & & & & & $\mathrm{x}$ & & \\
\hline ISO 10075-3 (2004) & & & & & & & & & & & $\mathrm{x}$ & $\mathrm{x}$ & & & & & & & $\mathrm{x}$ & & & \\
\hline Schnederman (2005) & $\mathrm{x}$ & & $\mathrm{x}$ & & & & $\mathrm{x}$ & & & & $\mathrm{x}$ & & & $\mathrm{x}$ & & & & $\mathrm{x}$ & $\mathrm{x}$ & & & $\mathrm{x}$ \\
\hline Stone (2005) & & $\mathrm{x}$ & & & & $\mathrm{x}$ & $\mathrm{x}$ & & & & $\mathrm{x}$ & & $\mathrm{x}$ & & & & & & & & $\mathrm{x}$ & \\
\hline Johnson (2008) & $\mathrm{x}$ & & $\mathrm{x}$ & & & $\mathrm{x}$ & & & & $\mathrm{x}$ & $\mathrm{x}$ & & & & & & & & & & & \\
\hline ISO 9241-171 (2008) & & & & & & & & & & $\mathrm{x}$ & & $\mathrm{x}$ & & & & & & $\mathrm{x}$ & $\mathrm{x}$ & & $\mathrm{x}$ & $\mathrm{x}$ \\
\hline ISO 9241-210 (2010) & & & & & & & & & & & & $\mathrm{x}$ & & & & & & & $\mathrm{x}$ & & $\mathrm{x}$ & $\mathrm{x}$ \\
\hline ISO 25010 (2011) & & $\mathrm{x}$ & $\mathrm{x}$ & $\mathrm{x}$ & & $\mathrm{x}$ & & $\mathrm{x}$ & & & $\mathrm{x}$ & $\mathrm{x}$ & & & & & $\mathrm{x}$ & & $\mathrm{x}$ & & $\mathrm{x}$ & \\
\hline Tognazzini (2014) & & $\mathrm{x}$ & $\mathrm{x}$ & & $\mathrm{x}$ & $\mathrm{x}$ & & $\mathrm{x}$ & & & $\mathrm{x}$ & $\mathrm{x}$ & & & & $\mathrm{x}$ & $\mathrm{x}$ & & & $x$ & & \\
\hline
\end{tabular}

Other usability criteria like Bastien's eight principles [5], include Norman's seven Rules [11], Shneiderman's eight golden rules [8], Stone's eight rules [12], Johnson's eight principles [13] and Tricot's ten rules [4] as well as the standards adopted by the International Committee ISO, namely, ISO 9241-11 standard's eleven principles [22], ISO 10075-3 standard's eight characteristics [21], ISO 9241-171 standard's thirty-eight criteria [24], ISO 9241-210 standard's eighteen rules [23] and ISO 9126-1 standard's principles [20], which were developed in 2001 and revised in 2011 by ISO 25010 [18].

Tognazzini's nineteen first principles of user interface design that were originally developed in 2003 and revised in 2014 [10] largely overlap with each other. They basically redefine and reorder the same principles, as is also the case with other less known usability criteria like Aaron's [15], Gerhardt-Powals's [17], Brown's [14], and Backer's [16].

In Table X, we selected the basic criteria that constitute the cornerstones of the usability dimension and placed them in comparison with user characteristics established by different studies, depending on possible declensions of the cited criteria, to deduce the most important usability criteria for evaluation of e-learning platforms.

We selected (see Figure 3 ) the most affordable usability criteria identified by the different studies. The seven usability criteria recommended in most studies are

- Status visibility

- Errors control

- Consistency / Coherence

- Efficiency / Flexibility

- Simplicity
- Guidance / Feedback

- Effectiveness / Reliability

Subsequently, we put these selected criteria, in comparison with users' characteristics established by different studies, see Table X. After analysis, we found that the usability requirements of ISO 25010 standard correspond correctly with most selected criteria, except the criterion "Feedback." However, "Feedback" has a great importance in evaluating e-learning platforms. For this, we retained the usability criteria of ISO 25010 by adding "Feedback" as part of our evaluation process.

In Table XI, we present the selected usability criteria.

\section{FREQUENCY OF USE USABILITY CRITERIA}

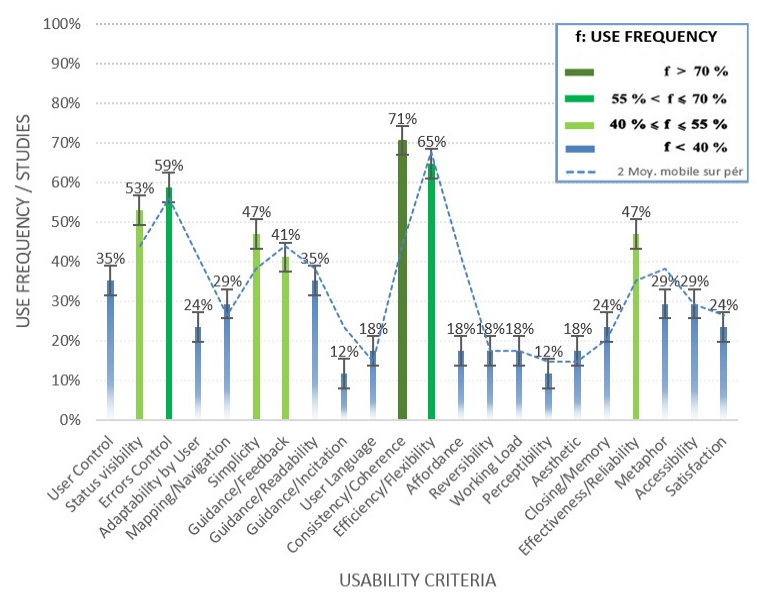

Figure 3. Analysis of usability criteria 


\section{Evaluation approach of platforms}

To be used effectively, all e-learning platforms need utility and usability components to be well exploited and used in the best conditions. These preconditions are known and presented in different forms. The element of requirements covers a set of specifications, such as functional suitability tools (Table IV), performance efficiency tools (Table V), compatibility tools (Table VI), security tools (Table VII), maintainability tools (Table VIII) and portability tools (Table IX) as well as the usability criteria (Table XI).

We present the evaluation approach to determine the quality of the platforms (Table XII) in an overview of the dimensions of utility and usability and the adapted criteria for evaluating the e-learning platforms.

In a similar fashion, we present Figure 4, a quality model of our main evaluation criteria of e-learning platforms, which were inspired from two dimensions: utility and usability.

\section{CONCLUSION}

Evaluation of e-learning platforms was the subject of an experiment. The actions of the learners and the interactions among them and with their tutors constituted a means for appreciating the achievement of the training goals.

This approach set up tags for exploration of e-learning platforms. It organized and prepared our comparative study to assess e-learning platforms and allowed us to live the experience of distance training via a suitable platform on which we built our judgment of the relevance of the teaching and technological choices and meeting most of our expectations.

In this perspective, experimentation proved essential to validate what was developed in the context of this article.
TABLE XI. USABILITY CRITERIA RETAINED

\begin{tabular}{|l|l|l|}
\hline \multicolumn{1}{|c|}{ Usability criteria } & YES & NO \\
\hline Appropriateness recognizability & & \\
\hline Learnability & & \\
\hline Operability & & \\
\hline User error protection & & \\
\hline User interface aesthetics & & \\
\hline Accessibility & & \\
\hline Reliability & & \\
\hline Guidance / Feedback & & \\
\hline
\end{tabular}

TABLE XII.

EVALUATION APPROACH OF THE E-LEARNING PLATFORMS QUALITY

\begin{tabular}{|l|}
\multicolumn{1}{c|}{$\begin{array}{c}\text { Assessment and analysis grid of the quality } \\
\text { of e-learning platforms } \\
\text { Identification of the platform }\end{array}$} \\
\hline Platform's name: \\
\hline Platform designer: \\
\hline Platform type: \\
\hline Platform genre: \\
\hline Platform's pedagogical model:: \\
\hline Platform license: \\
\hline Description: \\
\hline Version \& Edition: \\
\hline Used technology: \\
\hline Language: \\
\hline Website: \\
\hline Utility Specifications \\
\hline Functional suitability tools (Table 4) \\
\hline Performance efficiency tools (Table 5) \\
\hline Compatibility tools (Table 6) \\
\hline Security tools (Table 7) \\
\hline Maintainability tools (Table 8) \\
\hline Portability tools (Table 9) \\
\hline Usability Specifications \\
\hline Usability criteria (Table 11) \\
\hline
\end{tabular}

Evaluation of an e-learning platform

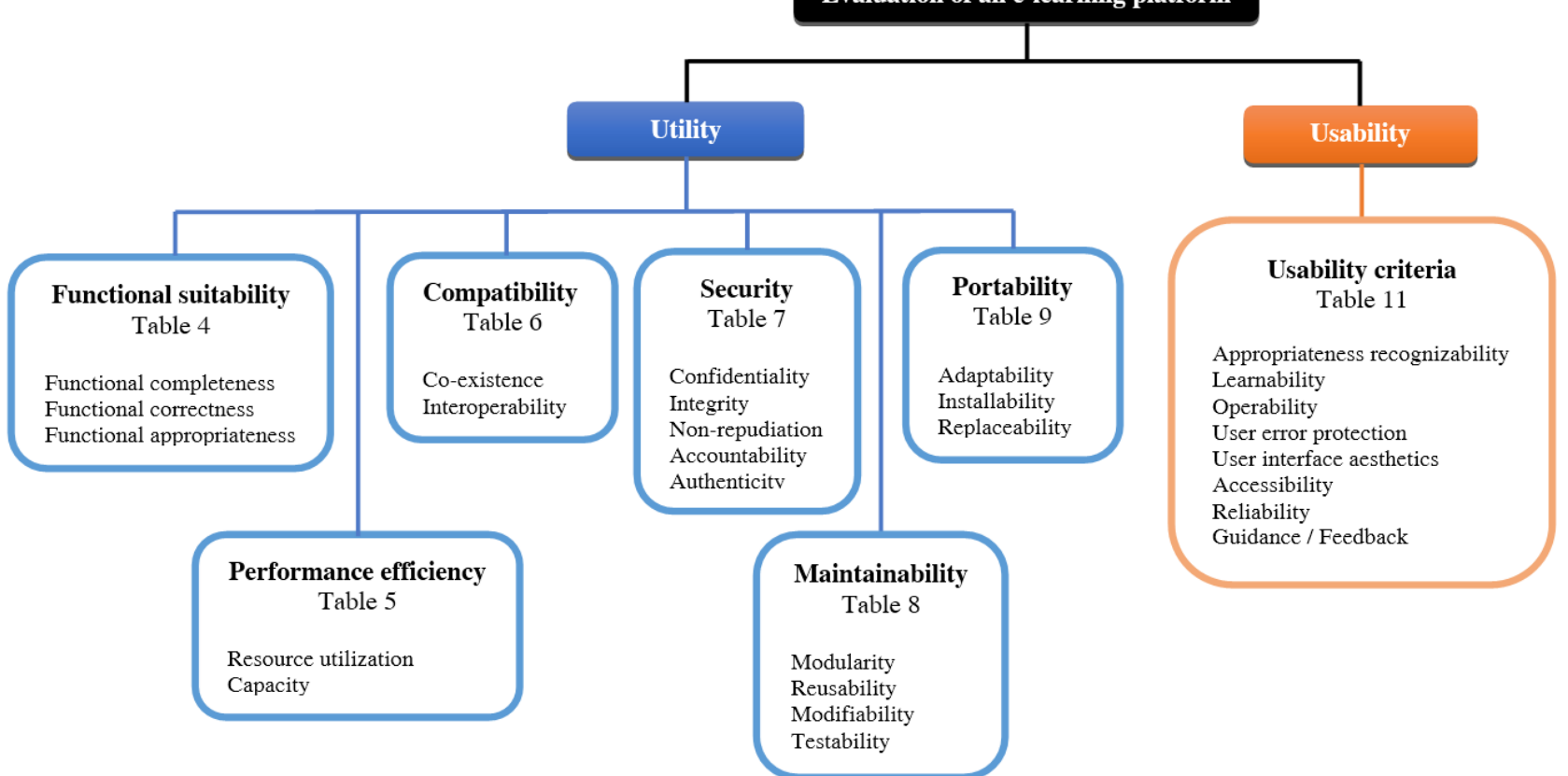

Figure 4. Quality model selected for choosing an e-learning platform 


\section{REFERENCES}

[1] Bastien, J.M.C. and Scapin, D.L. (2001). Evaluation des systèmes d'information et critères ergonomiques. In Kolski C. (dir.), Environnements évolués et évaluation de l'IHM, Interaction homme-machine pour les SI 2, Hermès Sciences Publications, Paris, 53-80

[2] Huart, J., Kolski, C. \& Bastien, C. (2008). L'évaluation de documents multimédias. Etat de l'art. In Leleu-Merviel (dir.), Objectiver l'humain? Volume 1, Qualification, quantification, Paris, Hermès Sciences Publications. Revue des Interactions Humaines Médiatisées Vol 9 N², 200852

[3] Senach, B. (1993). L'évaluation ergonomique des interfaces homme-machine: une revue de la littérature. In Sperandio, J.C. (Ed.), L'ergonomie dans la conception des projets informatiques, Toulouse, Octares éditions, 69-122

[4] Tricot, A., Plégat-Soutjis, F., Camps, J.F., Amiel, A., Lutz, G. \& Morcillo, A. (2003). Utilité, utilisabilité, acceptabilité: interpréter les relations entre trois dimensions de l'évaluation des EIAH. In Desmoulins, C., Marquet, P., Bouhineau, D. (Eds.), Environnements informatiques pour l'apprentissage humain, ATIEF / INRP éditions, Paris, 391-402

[5] Bastien, J.M.C., Scapin, D. (1993) Ergonomic Criteria for the Evaluation of Human-Computer interfaces. Institut National de recherche en informatique et en automatique, France

[6] A. Lablidi, A. Abourrich and M. Talbi, (dec-2009) «Démarche préconisée pour évaluer une plate-forme", Association EPI, [Online]. Available: www.epi.asso.fr/revue/articles/a0912b.htm [Accessed: 29-Apr-2014]: 2000 study: Étude comparative technique et pédagogique des plateformes pour la formation ouverte et à distance. [Study conducted by OVAREP (Observatoire des ressources multimédias)]

[7] Aska, Le Préau \& Klr.fr (2000). «Choisir une solution de téléformation : 2000 study : l'offre de plates-formes et de portails de téléformation » / [Study conducted by Anne Bouthry, Patrick Chevalier, Serge Ravet, et al.]

[8] Shneiderman, Ben, and Catherine Plaisant. 2005. Designing the user interface: strategies for effective human-computer interaction. Boston: Pearson/Addison Wesley

[9] J. Nielsen. (1995), « 10 Heuristics for User Interface Design: Article by Jakob Nielsen $»$. [Online]. Available: http:/www.nngroup.com/articles/ten-usability-heuristics/

[10] B. Tognazzini. (2014), «First Principles of Interaction Design (Revised \& Expanded) | askTog ». [Online]. Available: http://asktog.com/atc/principles-of-interaction-design/

[11] Norman, Donald A. 1988. The psychology of everyday things. New York: Basic Book

[12] Stone, Deborah L. 2005. User interface design and evaluation San Francisco, CA: Elsevier/Morgan Kaufmann

[13] Johnson, Jeff. 2008. "GUI bloopers 2.0 common user interface design don'ts and dos." in The Morgan Kaufmann series in interactive technologies. Amsterdam; Boston: Elsevier/Morgan Kaufmann

[14] Brown, Marlin C. 1999. Human-Computer Interface Design Guidelines Wiltshire: Intellect Boks

[15] Marcus, Aaron. 1992. Graphic Design for Electronic Documents and User Interfaces. New York: ACM
[16] Baker, K., Greenberg, S., \& Gutwin, C. (2002). Empirical development of a heuristic evaluation methodology for shared workspace groupware (pp. 96_105). In: Proceedings of the 2002 ACM conference on computer supported cooperative work (CSCW'02). New York, NY: ACM http://dx.doi.org/ 10.1145/587078.587093

[17] Gerhardt-Powals, J. (1996). Cognitive engineering principles for enhancing human-computer performance. International Journal of Human-Computer Interaction, 8(2), 189_221. http://dx.doi.org/10.1080/10447319609526147

[18] ISO/IEC 25010:2011. Systems and software engineering -Systems and software Quality Requirements and Evaluation (SQuaRE) -- System and software quality models

[19] The OVAREP (Observatoire des ressources multimédias), 2000 "Étude comparative technique et pédagogique des plateformes pour la formation ouverte et à distance »

[20] ISO/IEC 9126-1:2001. Software Engineering -Software product quality -Part 1: Quality Model

[21] ISO 10075-3:2004. Ergonomic principles related to mental workload -- Part 3: Principles and requirements concerning methods for measuring and assessing mental workload

[22] ISO 9241-11:1998. Ergonomic requirements for office work with visual display terminals (VDTs) -- Part 11: Guidance on usability

[23] ISO 9241-210:2010. Ergonomics of human-system interaction -Part 210: Human-centred design for interactive systems

[24] ISO 9241-171:2008. Ergonomics of human-system interaction -Part 171: Guidance on software accessibility

\section{AUTHORS}

Mohammed Ouadoud is with Laboratory of Informatics, Research Operational and Statistic Applied (LIROSA) at Faculty of Sciences, Abdelmalek Essaadi University, Tetouan, Morocco. (E-mail: mohammed.ouadoud@gmail.com).

Mohamed Yassin Chkouri is with Laboratory of the Information System and Software Engineering (SIGL) at National School of Applied Sciences, Abdelmalek Essaadi University, Tetouan, Morocco. (E-mail: yassin.chkouri@gmail.com).

Amel Nejjari is with Laboratory of the Information System and Software Engineering (SIGL) at National School of Applied Sciences, Abdelmalek Essaadi University, Tetouan, Morocco. (E-mail: amelnejjari@yahoo.fr).

Kamal Eddine El Kadiri is with Laboratory of Informatics, Research Operational and Statistic Applied (LIROSA) at Faculty of Sciences, Abdelmalek Essaadi University, Tetouan, Morocco. (E-mail: kamalelkadiri@yahoo.fr).

Submitted, 1 August 2015. Published as resubmitted by the authors on 04 November 2015. 